\title{
Shaping ceramics through indirect Selective Laser Sintering
}

Dr. ir. Jan Deckers*, Dr. ir. Khuram Shahzad, Prof. dr. Ludwig Cardon, Dr. ir. Marleen Rombouts, Prof. dr. Jef Vleugels, Prof. dr. Jean-Pierre Kruth

Rapid Prototyping Jounal, vol 20, issue 4

* corresponding author: deckersjan@gmail.com 


\section{INTRODUCTION}

Ceramic components are currently not as widely used in industry as they should and could be. The main reason for the reluctance in industry is the high, both fixed and variable, production costs of ceramic parts. Since additive manufacturing (AM) has the ability to produce near-net-shape ceramic functional prototypes, it has the ability to drastically reduce the fixed costs associated with the engineering of a ceramic part for a certain application. Moreover, as for all AM technologies, AM of ceramics has also the potential to shape freeform geometries, which cannot be produced by any other conventional production method.

There are basically two different categories of AM processes according to the ISO/ASTM 17296 standard (ISO/ASTM): (i) the direct processes, also called 'single-step' processes, in which parts are fabricated in a single operation where the basic geometrical shape and basic material properties of the intended product are achieved simultaneously and (ii) the indirect processes, also called 'multi-step' processes, in which the parts are fabricated in two or more operations, where the first typically provides the basic geometric shape and the following consolidates the part to the intended basic material properties. The advantage of the indirect AM processes, which mostly make use of a polymer binder material, is the ability to produce different types of ceramic materials. However, the indirect processes require a time consuming post-processing e.g. binder removal and sintering step. Therefore, indirect AM processes cannot produce ceramic parts rapidly. On the contrary, the direct AM processes, which do not use a binder material, do not require a time consuming post-processing step. Therefore, direct AM processes can produce ceramic parts more rapidly compared to indirect AM processes. However, the direct $\mathrm{AM}$ processes are currently not able to produce as many different types of ceramics as the indirect $\mathrm{AM}$ processes.

This paper gives a comparative study of various ceramic production routes in which indirect selective laser sintering (indirect SLS) is chosen as the AM process. The study starts from a basic powder metallurgy (PM) process, further denoted as 'the standard PM process', consisting of the following main steps: powder production, conventional SLS as shaping step to produce the so called 'green' parts, debinding and furnace sintering.

Many different ceramics have already been produced through this PM process, using indirect SLS of dry composite ceramic-binder powder particles as shaping step: a.o. $\mathrm{Al}_{2} \mathrm{O}_{3}$ (Liu et al., 2007b, Subramanian et al., 1995), $\mathrm{Al}_{2} \mathrm{O}_{3}-\mathrm{B}_{2} \mathrm{O}_{3}$ (Lee, 2002), $\mathrm{Al}_{2} \mathrm{O}_{3}-$ glass $-\mathrm{B}_{2} \mathrm{O}_{3}$ (Lee, 1998), $\mathrm{Al}_{2} \mathrm{O}_{3}-\mathrm{ZrO}_{2}-\mathrm{TiC}$ (Bai et al., 2005), apatite-mullite (Goodridge et al., 2007), graphite (Chakravarthy and Bourell, 2010), $\mathrm{K}_{2} \mathrm{O}-\mathrm{Al}_{2} \mathrm{O}_{3}-\mathrm{SiO}_{2}$ ( $\mathrm{Liu}$ et al., 2010), $\mathrm{SiO} 2$ (Agarwala et al., 1999), SiC (Evans, 2005, Stevinson et al., 2006a, Stevinson et al., 2006b), ZrO2 (Agarwala et al., 1999) and $\mathrm{ZrB}_{2}$ (Leu et al., 2012). Since alumina is the most commonly used ceramic for technical applications (Freedonia Group, 2007), a-alumina is chosen as primary ceramic material for this research. 
Indirect SLS with the use of a sacrificial binder phase has been already vastly studied. Different types of sacrificial organic binders have been examined to fabricate ceramic parts via SLS like long chain fatty acids (e.g. stearic acid (Leu et al., 2012, Liu et al., 2007b)), waxes (Bai et al., 2005), thermosets (Agarwala et al., 1999, Evans, 2005, Liu et al., 2010, Stevinson et al., 2006a, Stevinson et al., 2006b) and thermoplastics (Subramanian et al., 1995, Goodridge et al., 2007). Sometimes, a combination of binders is used: e.g. a thermoset in combination with semi-crystalline PA-11 (or nylon 11) to produce graphite (Chakravarthy and Bourell, 2010), or a wax in combination with amorphous thermoplast PMMA to produce the composite ceramic $\mathrm{Al}_{2} \mathrm{O}_{3}-\mathrm{ZrO}_{2}-\mathrm{TiC}(\mathrm{Bai}$ et al., 2005).

In order to produce ceramic parts with increased density, the following densification techniques are investigated as additional steps of the 'standard' PM process: laser remelting, isostatic pressing and infiltration.

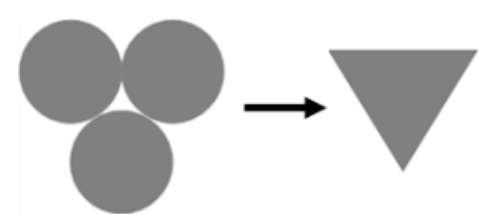

(a)

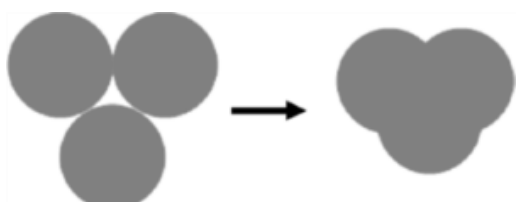

(b)

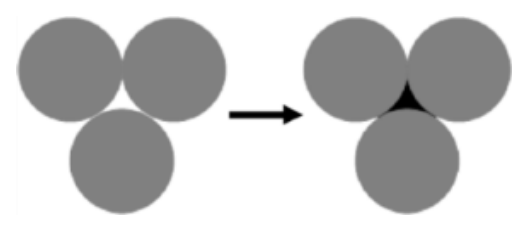

(c)

Figure 1: Schematic of the different investigated densification processes: remelting (a), isostatic pressing (b) and infiltration (c).

\subsection{Laser remelting}

Remelting means to laser scan the powder layers multiple times instead of only once. Remelting is vastly studied for Selective Laser Melting (SLM) of metals. It is used to improve the part properties like surface roughness, hardness and density (Kruth et al., 2009, Kruth et al., 2008a, Kruth et al., 2008b, Yasa et al., 2011a, Yasa et al., 2011b). Through increasing the density of the green parts, remelting during SLS has the possibility to also improve the sintered density of the fabricated parts.

\subsection{Isostatic pressing}

During isostatic pressing (IP), an external pressure is applied to increase the density of the parts. Different IP techniques exist, which all differ in the sense that other pressure transferring media are used (Figure 2): cold isostatic pressing (CIP; a liquid at room temperature), quasi isostatic pressing (QIP; powder), warm isostatic pressing (WIP; a heated liquid) and hot isostatic pressing (HIP; a high temperature gas). CIP, QIP and WIP are generally applied on green parts before debinding and solid state furnace sintering. Prior to the CIP and WIP process, the green parts are encapsulated in a vacuum atmosphere. 


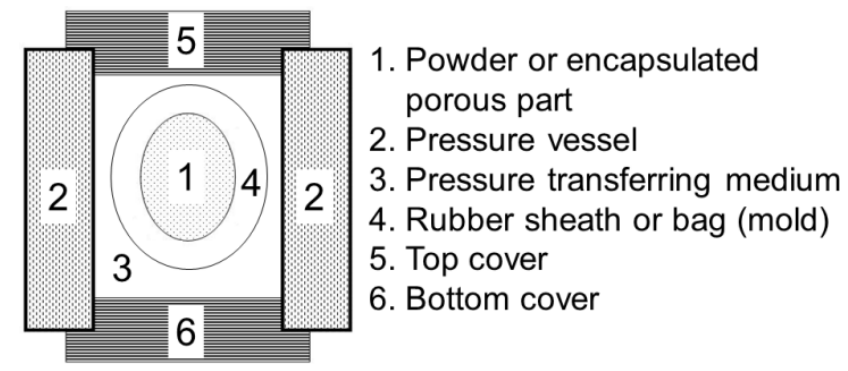

Figure 2: Schematic illustration of different IP techniques: (wet bag) cold isostatic pressing 'CIP', warm isostatic pressing 'WIP' and quasi isostatic pressing 'QIP'. QIP does not use a rubber sheath or bag to encapsulate the powder/SLSed part.

\subsubsection{Cold isostatic pressing}

Cold isostatic pressing (CIP) is commercially used to produce homogeneous and high density (up to 60\%) green powder compacts with increased shape complexity by applying pressure from multiple directions. The CIP technology can be divided into a wet bag or dry bag approach. During wet bag isostatic pressing, the CIPing method used in the research, the powder is encapsulated in a rubber sheath or bag (mould) that is immersed in a liquid that transmits the pressure uniformly to the powder (Figure 2). Dry bag presses have a bag as an integral part of the pressure vessel and are used when many parts of simple geometry have to be made.

Combined indirect SLS and wet bag CIPing can be used as a net shaping technique to produce dense parts. CIPing has been used to produce AISI 304 stainless steel parts by SLS (Du et al., 2010, Liu et al., 2007a, Lu et al., 2008). CIP has also been used to densify ceramic components produced through 3D printing (Yoo et al., 1993) and SLS (Liu et al., 2010).

\subsubsection{Quasi isostatic pressing}

During quasi isostatic pressing (QIP), a process which is also known as the Ceracon process (Lu et al., 2008, Olevsky et al., 2007), powder particles are used instead of a liquid as pressure transmitting medium (Figure 2). It is not needed to encapsulate SLSed samples in a rubber sheath or bag (mold) before isostatically pressing. Moreover, QIPing can be performed at elevated temperatures, which enable the organic binder to plastically deform during isostatic pressing. On the other hand, since the pressure is only applied in one direction during the QIP process, the concomitant shrinkage is non-uniform. The non-isostatic stress state will in general result in shape distortion in addition to densification (Olevsky et al., 2007). Nevertheless, QIP has been used to fully densify alumina-glass composites fabricated by a selective laser sintering process (Lee, 1998).

\subsubsection{Warm isostatic pressing}

Although during warm isostatic pressing (WIP, Figure 2) the SLSed samples need to be encapsulated in a rubber sheath or bag (mold) before isostatically pressing, it combines the benefits of both CIP and QIP. By using 
a heated liquid as pressure transferring medium, an isostatic pressure can be uniformly applied on the SLSed sample and the binder material can be plastically deformed.

WIPing was already used to produce metal (Yang et al., 2004) and ceramic (Galusek et al., 2007) parts. WIPing has also been used to densify alumina parts produced through 3D printing (Yoo et al., 1993). Nevertheless, the combination of WIPing and indirect SLS is new.

\subsubsection{Hot isostatic pressing}

During HIP, the gas is generally heated to very high temperatures $\left(>800{ }^{\circ} \mathrm{C}\right)$. HIP is already studied in combination with SLS for the production of metal parts (Agarwala et al., 1999, Das et al., 1998a, Das et al., 1998b, Das et al., 1998c, Das et al., 1999, Liu et al., 2007a, Lu et al., 2008, Wohlert et al., 1999). Generally, vacuum encapsulating of the SLSed parts in a metal container or can is applied before the HIPing step (i.e. exsitu canning). In-situ encapsulating by direct sintering of an integral, dense, gas impermeable skin or 'can' at the part boundaries under vacuum atmosphere has also been investigated (Das et al., 1998a, Das et al., 1998b, Das et al., 1998c, Das et al., 1999, Wohlert et al., 1999).

\subsubsection{Discussion}

In this research CIP, QIP and WIP were investigated as possible IP techniques to increase the density of the final parts. No experiments which combine SLS and HIP were performed. It would be very difficult to eliminate the adverse container-part interactions if ex-situ HIPing would be applied. The aim was rather to investigate the additive production of closed porosity alumina parts which can be HIPed in future research, without applying the ex-situ 'canning' step.

\subsection{Infiltration}

Infiltration methods were successfully used to increase the final density of parts, produced through indirect SLS. As an example, Stevinson et al. (Stevinson et al., 2006a) infiltrated SiC ceramic preforms with Si. Further, Subramanian et al. (Subramanian et al., 1995) reported that green part infiltration with small quantities of alumina colloids largely improved the green part strength during debinding and solid state sintering.

In this paper, the idea of Subramanian is further explored by infiltrating green parts, pre-sintered parts and/or solid state sintered parts (SSS parts) with stable suspensions containing submicrometer $\alpha$-alumina particles (grade SM8, Baikowski, France ). Moreover, pressureless infiltration tests, as well as pressure infiltration and vacuum infiltration tests were performed (Figure 3). During the pressureless infiltration experiments, the parts were dipped, without applying an external pressure, into a suspension. During the pressure infiltration experiments, the parts were first dipped into an alumina suspension. Secondly, an external pressure was applied to squeeze the suspension into the porosities of the parts. During vacuum infiltration, a vacuum atmosphere was applied before infiltrating the parts at atmospheric pressure. 
W.C. Tu and F.E. Lange (Tu and Lange, 1995) derived the following formula, that describes the total driving force for the infiltration, $p_{d}$, as a function of the applied pressure.

$$
p_{d}=p_{c}+p_{a}-p_{i} \quad \text { Equation } 1
$$

The infiltration of porous parts with a suspension is driven by two different mechanisms. The first involves the flow of infiltrating liquid into the porous structure under the combined effect of the capillary $\left(p_{c}\right)$ and applied pressure $\left(\mathrm{p}_{\mathrm{a}}\right.$, consisting of the hydrostatic and atmospheric pressure) until the internal pressure $\left(\mathrm{p}_{\mathrm{i}}\right)$ of the compressed air becomes equal to $\mathrm{p}_{\mathrm{a}}+\mathrm{p}_{\mathrm{c}}$. The second mechanism involves the outward diffusion of gas because of its higher solubility at higher pressures. During pressureless infiltration $\left(p_{a}=1 \mathrm{~atm}\right)$ experiments, infiltration is mainly driven by the first mechanism: $p_{c}+p_{a}(1 \mathrm{~atm})=p_{i}$. When applying pressure infiltration $\left(p_{a}>1\right.$ atm $)$, infiltration is also driven by the second mechanism (i.e. diffusion of air). This leads to a better infiltration behavior. When applying vacuum infiltration $\left(p_{i} \approx 0\right.$ atm; $\left.p_{a}=1 \mathrm{~atm}\right)$, the air inside the pores of the SLSed is evacuated before infiltration. In this case, infiltration is again determined by the first mechanism: $p_{c}+p_{a}(1$ atm $)=p_{i}(0$ atm $)$.

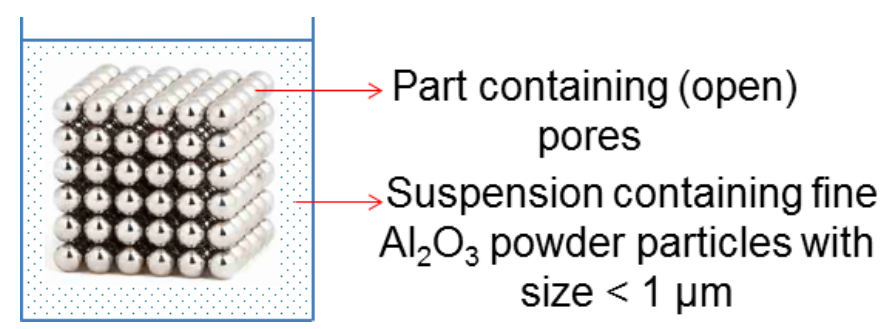

Figure 3: Schematic of the infiltration process.

\section{EXPERIMENTAL PROCEDURES}

Figure 4 is a schematic representation of all steps of the powder metallurgy processing routes investigated in this paper to produce ceramic parts. In this section, the experimental procedures to investigate these steps are detailed.

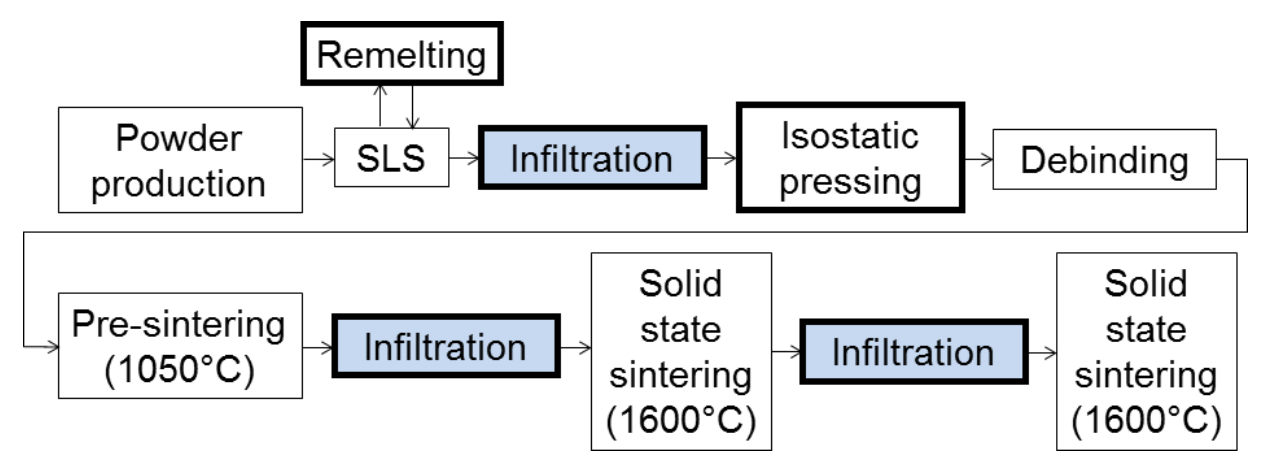

Figure 4: Powder metallurgy (PM) processing flow chart, illustrating the investigated process steps. The chart also illustrates at which stages of the PM process the different densification steps were performed. 


\subsection{Powder production}

As the SLS machine was equipped with a counter current roller for the deposition of dry powders, different powders had to be developed. Five different alumina containing composite powders were produced by four powder production methods (Table 1): ball milling (Deckers et al., 2012b), dispersion polymerization - cake formation - ball milling (Deckers et al., 2013, Cardon et al., 2013), thermally induced phase separation (TIPS1 (Deckers et al., 2012a, Shahzad et al., 2012, Shahzad et al., 2013)) and thermally induced phase separation cake formation - ball milling (TIPS2) (Rombouts et al., 2012). The five composite powders had different binder materials and a different amount of binder: polyamide (PA, 53vol\% (Deckers et al., 2012b) and 60vol\% (Shahzad et al., 2012, Deckers et al., 2012a)), amorphous polystyrene (PS, 71vol\%) (Cardon et al., 2013, Deckers et al., 2013), polypropylene (PP, 60vol\%) (Shahzad et al., 2013) and a 82 wt\% carnauba wax - 18 wt\% low density polyethylene combination (carn.+LDPE, 54vol\% (Rombouts et al., 2012)). PA and PP were chosen as binder material since they have an 'SLS window' (Drummer et al., 2010) due to their semi-crystalline behavior (PP has an SLS window at a lower temperature compared to PA). This SLS window improved the sinterability (i.e. the easiness to find appropriate SLS parameters) of the composite powders (Drummer et al., 2010, Kruth et al., 2007). PS was chosen due to its geometrical stability during the debinding step, and the carnauba wax containing binder for its low melt viscosity. The $\mathrm{Al}_{2} \mathrm{O}_{3}$ phase of the composite powder, containing the carnauba wax-low density polyethylene phase, was CT3000SG (Almatis $\mathrm{GmbH}$, Germany). The $\mathrm{Al}_{2} \mathrm{O}_{3}$ phase of all other composite powders was SM8 (Baikowski, France). Detailed descriptions of the various powder production routes can be found in literature (Deckers et al., 2012b, Cardon et al., 2013, Shahzad et al., 2012, Shahzad et al., 2013, Shahzad et al., 2014, Rombouts et al., 2012).

\subsection{Density measurements}

The density was assessed through measurements with an accurate balance (Analytical Balance, Sartorium, Germany). Unless stated differently, all densities reported in this paper were measured by the Archimedes method without lacquer, but with correction measurement for open porosities.

In order to calculate the relative densities of the parts obtained during the investigated PM processes, the absolute density of the $\mathrm{Al}_{2} \mathrm{O}_{3}$ was considered to be $3.984 \mathrm{~g} / \mathrm{cm}^{3}$ (Munro, 1997). The absolute density of PA, PS, $\mathrm{PP}$ and the carnauba wax - polyethylene combination were considered to be respectively $1.00 \mathrm{~g} / \mathrm{cm}^{3}$ (Duraform PA datasheet), $1.05 \mathrm{~g} / \mathrm{cm}^{3}, 0.90 \mathrm{~g} / \mathrm{cm}^{3}$ and $0.966 \mathrm{~g} / \mathrm{cm}^{3}$.

\subsection{Selective laser sintering}

Green samples were fabricated on a Sinterstation 2000 machine (DTM Corporation / 3DSystems, USA) equipped with a $100 \mathrm{~W} \mathrm{CO}_{2}$ laser (f100, Synrad, USA) with a wavelength of $10.6 \mu \mathrm{m}$ and a laser beam diameter $\phi_{1 / e^{2}}$ of $400 \mu \mathrm{m}$. Powder layers were deposited by a counter current roller. The powder layers were irradiated with 
the laser beam in $\mathrm{N}_{2}$ atmosphere (L'Air Liquide, Belgium, $\left[\mathrm{O}_{2}\right]<5 \%$ ). In order to improve the laser sinterability of the powder, the parts were produced at a powder bed of $\sim 53-175^{\circ} \mathrm{C}$. The energy required to melt the binder phase, was partly supplied by preheating of the powder bed (distributed cylinder heating and surface IR heating) and by extra laser irradiation which locally raised the temperature above the glass transition temperature $\left(T_{g}\right)$.

Besides SLS tests to investigate the powder production route and to investigate the powder preheating and cooling conditions, a parametrical study was performed to investigate other crucial SLS parameters. In this parametrical study cubic parts of $10 \times 10 \times 10 \mathrm{~mm}^{3}$ or $15 \times 15 \times 15 \mathrm{~mm}^{3}$ were produced with a laser power ' $\mathrm{P}$ ', scan speed 'v', scan spacing 's' and layer thickness 'l' varying between respectively 3-17 W, 300-1250 mm/s, 80-500 $\mu \mathrm{m}$ and 80-250 $\mu \mathrm{m}$. The laser energy density, e, defined as $\mathrm{P} /(\mathrm{svl})$, was varied from 0.03-2.92 $\mathrm{J} / \mathrm{mm}^{3}$.

\subsection{Debinding and sintering}

In the debinding step, the polymer binder was removed from the green parts and a brown part was formed. A heating rate of $0.1^{\circ} \mathrm{C} / \mathrm{min}$ was applied with a 2 hours dwell time at $600^{\circ} \mathrm{C}$ in air, followed by a natural furnace cooling. Afterwards the submicrometer alumina particles of the brown part were solid state sintered (SSS) to form a densified white part. In this second step a heating rate of $5^{\circ} \mathrm{C} / \mathrm{min}$ was applied with a dwell time of 2 hours at $1600^{\circ} \mathrm{C}$ in air, followed by a natural furnace cooling. Sometimes, pre-sintering was used to strengthen the brown parts by forming necks between the submicrometer particles, i.e. the initial step of the solid state sintering process, at a heating rate of $5^{\circ} \mathrm{C} / \mathrm{min}$ and dwell time of 2 hours at $1050^{\circ} \mathrm{C}$ in air.

\subsection{Densification processes}

\subsubsection{Remelting}

The $\mathrm{Al}_{2} \mathrm{O}_{3}-\mathrm{PA}$ composite powder, produced through temperature induced phase separation (TIPS1, Table 1), was processed using remelting as densification technique. During these remelting experiments, every powder layer of $150 \mu \mathrm{m}$ thickness 'l' was scanned once with the optimized parameter set for SLS (5 W laser power 'P', $600 \mathrm{~mm} / \mathrm{s}$ scan speed ' $\mathrm{v}$ ', $150 \mu \mathrm{m}$ scan spacing 's') and also one or two times with different remelting parameters. The remelting parameters were: a laser power of 5-10 W, a scan speed of $320-1280 \mathrm{~mm} / \mathrm{s}$ and a scan spacing of $150 \mu \mathrm{m}$. In total, 18 cubic alumina parts $\left(10 \times 10 \times 10 \mathrm{~mm}^{3}\right.$, Table 2: parts 6 to 23$)$ were produced with remelting.

\subsubsection{Isostatic pressing}

For cold (CIP) and warm (WIP) isostatic pressing experiments, the SLSed parts were first vacuum packed in a rubber bag. CIP experiments were performed on parts SLSed with the $\mathrm{Al}_{2} \mathrm{O}_{3}-\mathrm{PA}$ powder produced through ball milling (Table 2: parts 24 to 32) and the TIPS method (Table 2: parts 33 to 36). During these experiments, an external pressure of 100-200 MPa was applied for 1-5 minutes in water (CIP, EPSI, Belgium). WIPing experiments were performed on parts SLSed with the $\mathrm{Al}_{2} \mathrm{O}_{3}-\mathrm{PS}$ (Table 2: parts 43 and 44), $\mathrm{Al}_{2} \mathrm{O}_{3}-\mathrm{PA}$ (TIPS, Table

2: part 45), $\mathrm{Al}_{2} \mathrm{O}_{3}-\mathrm{PP}$ (Table 2: parts 46 and 47) and $\mathrm{Al}_{2} \mathrm{O}_{3}$-carn.-PE powders (Table 2: part 48). WIPing 
experiments were performed for 5-30 minutes in a home-made die/punch set-up with external heating element and silicone oil as pressurising medium. The temperature and pressure of the WIPing experiments varied respectively between $60-140^{\circ} \mathrm{C}$ and $16-64 \mathrm{MPa}$. Quasi isostatic pressing (QIP) experiments were performed in a similar punch/die set-up with external heating element using $\mathrm{Al}_{2} \mathrm{O}_{3}$ powder as pressurising medium. The time, temperature and pressure of the QIPing experiments varied respectively between $5-30$ minutes, $100-164^{\circ} \mathrm{C}$ and 20-50 MPa. Just like the CIP experiments, the QIP experiments were performed on parts SLSed with the $\mathrm{Al}_{2} \mathrm{O}_{3}$ PA powder produced through ball milling (Table 2: parts 37 and 38) and the TIPS method (Table 2: parts 39 to 42).

\subsubsection{Infiltration}

During the pressureless infiltration experiments, which were performed on parts SLSed with the $\mathrm{Al}_{2} \mathrm{O}_{3}-\mathrm{PA}$ (TIPS) and $\mathrm{Al}_{2} \mathrm{O}_{3}-\mathrm{PS}$ powders (Table 2: parts 49 to 52), the parts were dipped for 4 hours, into a 30 vol\% alumina containing suspension. During the pressure infiltration experiments, which were performed on parts SLSed with $\mathrm{Al}_{2} \mathrm{O}_{3}-\mathrm{PS}$ and $\mathrm{Al}_{2} \mathrm{O}_{3}-\mathrm{PP}$ powders (Table 2: parts 53 to 57 ), the parts were first dipped into a $30-40$ vol\% alumina suspension. Secondly, an external pressure of 2-48 MPa was applied for about 1-5 minutes. One part (Table 2: part 58) was produced by combining WIP and pressure infiltration. During the vacuum infiltration experiments, which were performed on parts SLSed with the $\mathrm{Al}_{2} \mathrm{O}_{3}-\mathrm{PP}$ and $\mathrm{Al}_{2} \mathrm{O}_{3}$-carn.+PE powders (Table 2: parts 59 to 66), a vacuum atmosphere (5800 Pa) was applied before infiltrating for 100 seconds with a 40 vol\% suspension. At last, four parts (Table 2: parts 67 to 70) were produced by combining WIP and vacuum infiltration.

All suspensions were stabilized with 0.3 wt\% citric acid (Anhydrous p.a., Acros, USA) and mixed on a Turbula mixer (Type T2A, WAB, Basel, Switzerland) for $24 \mathrm{hrs}$. Some parts (Table 2: parts 60 and 62 to 66) were infiltrated multiple times at a certain stage of the PM process. In this case the parts were dried, before infiltrating them again.

\section{RESULTS}

\subsection{Selective laser sintering}

When using the ball milled $\mathrm{Al}_{2} \mathrm{O}_{3}-\mathrm{PA}$ powder, no homogeneous powder layers could be deposited by the counter current roller of the DTM Sinterstation 2000 (Deckers et al., 2012b). This was in contrast with the other powders, which could be homogenously deposited by the counter current roller. Probably, the inhomogeneous layer deposition was caused by the irregular shape of the composite powder agglomerates (Figure 5a). As a result, the parts after SLS had a low green density (up to 37\%) and no complex shapes could be produced. Since the other composite powder agglomerates had a more spherical shape (Figure 5b), no problems occurred during deposition by the counter current roller. 


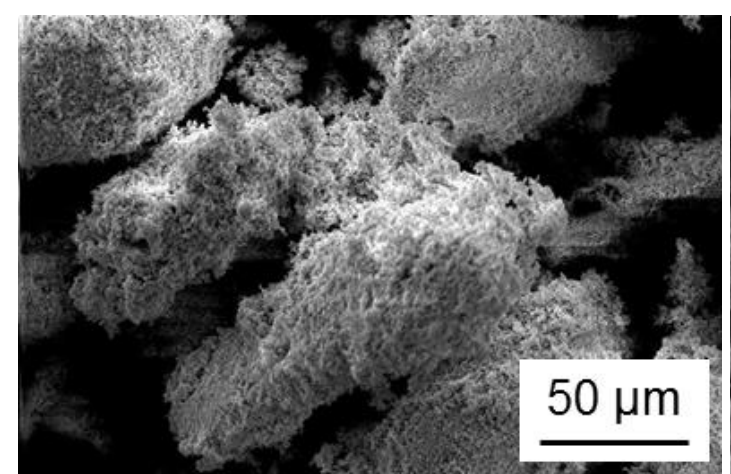

(a)

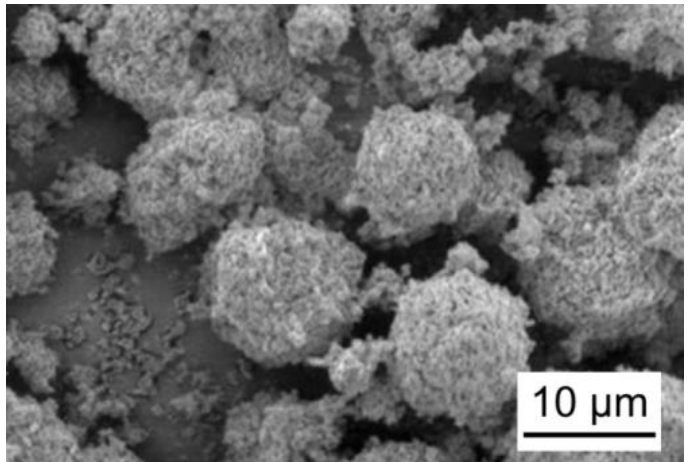

(b)

Figure 5: SEM micrographs of non-spherical $\mathrm{Al}_{2} \mathrm{O}_{3}$-PA powder produced through ball milling (a, (Deckers et al., 2012b)) and spherical $\mathrm{Al}_{2} \mathrm{O}_{3}$-PP powder produced through temperature induced phase separation (b, (Shahzad et al., 2013)).

Compared to the other powders, the $\mathrm{Al}_{2} \mathrm{O}_{3}$-carnauba wax-LDPE powder behaved differently during laser irradiation. Firstly, the melt pools tended to break up into balls (Figure 6a). This phenomenon, which is called 'balling', is commonly described as due to Rayleigh instabilities (Kruth et al., 2007). Probably, the low viscosity of the carnauba wax during irradiation caused the melt pools to break. The occurrence of balling could be avoided by producing the $\mathrm{Al}_{2} \mathrm{O}_{3}$-carnauba wax-LDPE parts on a cardboard base plate.

During laser irradiation, the $\mathrm{Al}_{2} \mathrm{O}_{3}$-carnauba wax-LDPE material also tended to curl, causing thermal cracks in the parts after SLS (Figure 6b). The curling of the parts during the SLS process might be related to the overlap between the melting onset temperature of carnauba wax and the recrystallization temperature of LDPE. As a result, no laser window could be defined for this binder system. According to the Quasi Isothermal Theory (Drummer et al., 2010), it was not possible to preheat this binder system up to a temperature where it stayed in a molten, stress-free state after laser irradiation, until all layers of the part were produced.

Due to the curling of the parts, the counter current roller hit the parts during layer deposition and tended to generate shear forces resulting in delamination as illustrated in Figure 6c. This could however also be prevented by using a base plate, which anchored the parts during SLS 
Table 1: Comparison of the composite powders assessed in this study, when applying them to the standard PM process (i.e. powder production, Selective Laser Sintering, debinding and solid state sintering) without postdensification treatment.

$(\mathrm{NM}=$ not measured $)$

\begin{tabular}{|c|c|c|c|c|c|c|}
\hline \multicolumn{2}{|c|}{ production method } & ball milling & $\begin{array}{l}\text { disp. } \\
\text { polym. }\end{array}$ & TIPS 1 & TIPS 1 & TIPS 2 \\
\hline \multicolumn{2}{|l|}{ ceramic } & $\mathrm{Al}_{2} \mathrm{O}_{3}$ & $\mathrm{Al}_{2} \mathrm{O}_{3}$ & $\mathrm{Al}_{2} \mathrm{O}_{3}$ & $\mathrm{Al}_{2} \mathrm{O}_{3}$ & $\mathrm{Al}_{2} \mathrm{O}_{3}$ \\
\hline \multirow{2}{*}{\multicolumn{2}{|c|}{ binder }} & PA & PS & PA & PP & carn.+LDPE \\
\hline & & $53 \mathrm{vol} \%$ & $71 \mathrm{vol} \%$ & $60 \mathrm{vol} \%$ & $60 \mathrm{vol} \%$ & $54 \mathrm{vol} \%$ \\
\hline \multicolumn{2}{|c|}{ Powder bed heating } & $\sim 175^{\circ} \mathrm{C}$ & $\sim 90^{\circ} \mathrm{C}$ & $\sim 175^{\circ} \mathrm{C}$ & $\sim 138^{\circ} \mathrm{C}$ & $\sim 75^{\circ} \mathrm{C}$ \\
\hline \multirow{6}{*}{ SLS } & deposition & poor & good & excellent & excellent & excellent \\
\hline & balling & no & no & no & no & yes \\
\hline & curling & no & no & no & no & yes \\
\hline & $\mathrm{e}_{\rho S L S}{ }^{\max }\left[\mathrm{J} / \mathrm{mm}^{3}\right]$ & 0.97 & 0.76 & 0.37 & 0.77 & 0.38 \\
\hline & $\mathrm{e}^{*}\left[\mathrm{~J} / \mathrm{mm}^{3}\right]$ & 1.94 & 0.76 & 0.37 & 0.12 & 0.38 \\
\hline & $\rho_{S L S}{ }^{e^{x}}$ & $37 \%$ & $66 \%$ & $55 \%$ & $51 \%$ & $66 \%$ \\
\hline \multirow{4}{*}{$\begin{array}{l}\text { Debinding } \\
\& \\
\text { sintering }\end{array}$} & $\Delta_{x-y} e^{*--}$ & NM & $-31 \%$ & $-21 \%$ & $-20 \%$ & $-21 \%$ \\
\hline & $\Delta_{\mathrm{z}}^{\mathrm{e}^{\mathrm{x}^{-}}}$ & NM & $-44 \%$ & $-24 \%$ & $-21 \%$ & $-26 \%$ \\
\hline & cracks $_{\text {deb+Sss }}$ & NM & yes & no & no & no \\
\hline & $\rho_{s s s}{ }^{e^{*}}$ & NM & $66 \%$ & $47 \%$ & $39 \%$ & $77 \%$ \\
\hline
\end{tabular}

$\mathrm{e}_{\rho S L S}{ }^{\max }=$ the laser energy density which led to the maximum green density (i.e. density after SLS)

$\mathrm{e}^{*}=$ optimized laser energy density

$\rho_{\mathrm{SLS}} \mathrm{e}^{*}=$ relative density after SLS for parts produced with optimized laser energy density

$\Delta_{x-y}{ }^{e^{*}}=\%$ linear shrinkage during debinding and SSS in the scan $\mathrm{x}$ and cross-scan $\mathrm{y}$ directions for parts SLSed with an optimized laser energy density

$\Delta_{\mathrm{z}}^{\mathrm{e}^{*}}=\%$ linear shrinkage during debinding and SSS in the $\mathrm{z}$ direction for parts SLSed with an optimized laser energy density

cracks $_{\text {deb+sss }}=$ cracking during debinding and solid state sintering: yes/no

$\rho_{S S S}{ }^{e^{*}}=$ relative density after SSS for parts produced with optimized laser energy density

TIPS 1 = thermally induced phase separation

TIPS 2 = thermally induced phase separation - cake formation - ball milling 


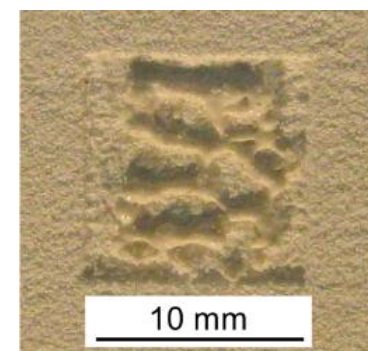

(a)

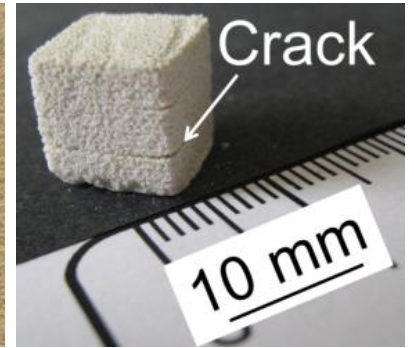

(b)

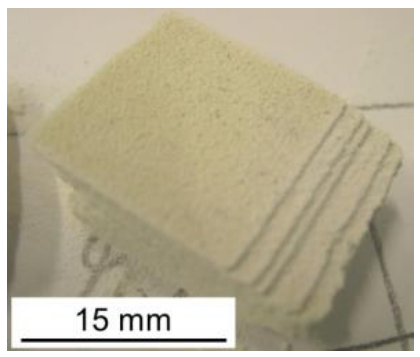

(c)

Figure 6: Different phenomena occurring during SLS of $\mathrm{Al}_{2} \mathrm{O}_{3}$-carnauba_wax-LDPE powder: balling (a), cracking (b) and delamination (c).

When using too low laser energy densities during SLS of the powder agglomerates, insufficient powder material was consolidated and the resulting parts were too fragile (Figure 7, left). When using higher laser energy densities, the binder material was heated more, causing a decrease of the binder viscosity. If the viscosity was too low, the binder material flowed into the underlying powder and towards the sides of the parts. As a result, a dross was formed at the part contours (Figure 7, middle). When too high laser energy densities were applied, the binder material started to degrade. The gases formed during binder degradation sometimes led to the formation of extra pores in the green parts (Figure 7, right). Both binder degradation and pore formation also resulted in too fragile parts. The green density and concomitant strength of the SLSed parts was a compromise between the material degradation, pore formation and plastic flowing of the binder material to bind the alumina particles.

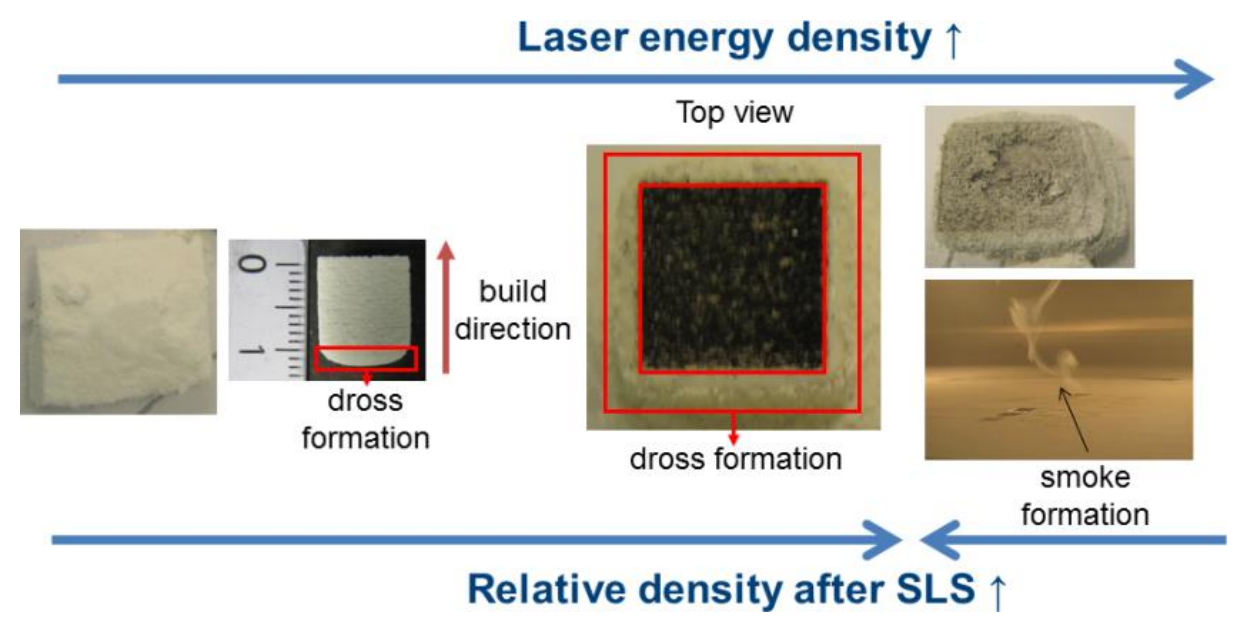

Figure 7: Influence of the laser energy density 'e' on the the relative density after SLS.

For the five investigated alumina containing composite powders, the laser energy density which led to the maximum green density ( $e_{\rho S L S}{ }^{\max }$, Table 1 ) varied from $0.37 \mathrm{~J} / \mathrm{mm}^{3}$ for the $\mathrm{Al}_{2} \mathrm{O}_{3}-\mathrm{PA}$ powder produced through TIPS up to $0.97 \mathrm{~J} / \mathrm{mm}^{3}$ for the $\mathrm{Al}_{2} \mathrm{O}_{3}-\mathrm{PA}$ powder produced through ball milling. This means that the powder production method, together with the amount of binder used, had a more pronounced influence on the SLS behavior than the binder material itself.

In general, the parts which had the highest green density after SLS, also had the highest green strength. The higher the green strength, the easier complex shaped parts could be fabricated without the risk of breaking them 
during manipulation. Nevertheless, not for all composite powders, the laser energy density was optimized for the highest green density. For the ball milled $\mathrm{Al}_{2} \mathrm{O}_{3}-\mathrm{PA}$ powder, the laser energy density was optimized to have the highest density after an additional cold isostatic pressing (CIP), debinding and solid state sintering (SSS) step. As the parts, SLSed with the highest laser energy densities contained the lowest amount of binder material due to binder degradation, these parts had the highest final density. For the $\mathrm{Al}_{2} \mathrm{O}_{3}-\mathrm{PP}$ powder, produced by the TIPS process, the laser energy density was optimized to have the highest geometrical accuracy (i.e. no dross formation) after SLS (Figure 8, left). The optimized laser energy density (e*, Table 1) of $0.12 \mathrm{~J} / \mathrm{mm}^{3}$, was lower than the laser energy density of $0.77 \mathrm{~J} / \mathrm{mm}^{3}$ which resulted in the highest green density (Figure 8 , right). In this case, the green density after SLS, corresponding to the optimized laser energy density ( $\rho_{S L S}{ }^{\mathrm{e}^{*}}$, Table 1 ), was $51 \%$.

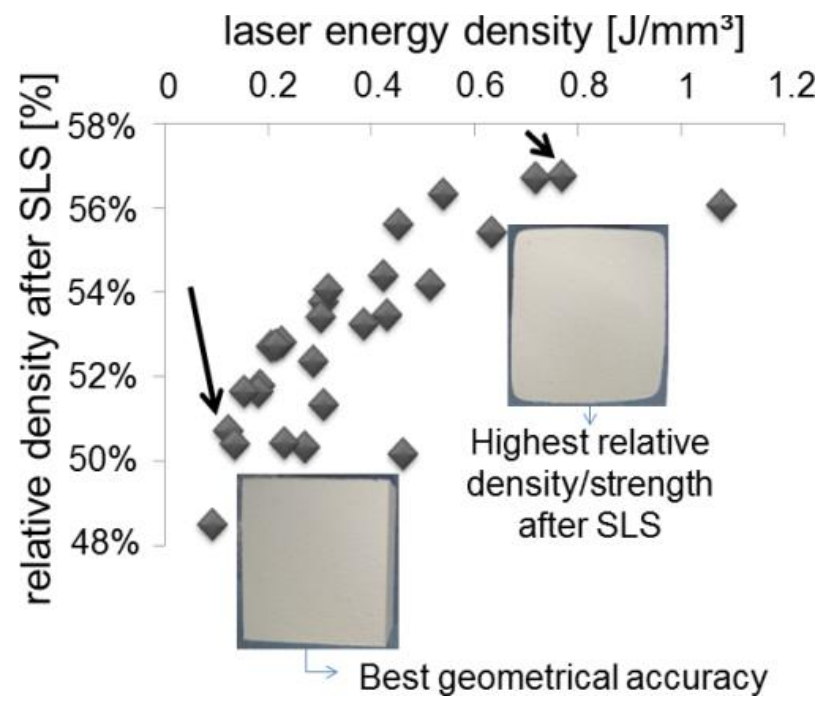

Figure 8: Relative density after SLS of the $\mathrm{Al}_{2} \mathrm{O}_{3}-\mathrm{PP}$ (TIPS 1) powder particles, as a function of the laser energy density during SLS. The laser energy density to SLS parts with best geometrical accuracy (left), is lower compared to the laser energy density to produce parts with the highest relative density and strength after SLS (right).

\subsection{Debinding and furnace sintering}

The shrinkage during debinding and solid state sintering (SSS) was generally comparable in the scan, $\mathrm{x}$, and cross-scan, y, directions, but larger in the build, $z$, direction (Figure 9): see $\Delta_{x-y}{ }^{e^{*}}$ and $\Delta_{z}{ }^{e^{*}}$ in Table 1. This was probably due to pores between the different SLSed layers, i.e. inter-layer pores.

The final density after debinding and solid state sintering of the parts SLSed with optimized laser energy densities $\left(\rho_{\text {sss }}{ }^{\mathrm{e}^{*}}\right)$, varied between $39 \%$ and $77 \%$. The solid state sintered parts (SSS parts) sometimes contained

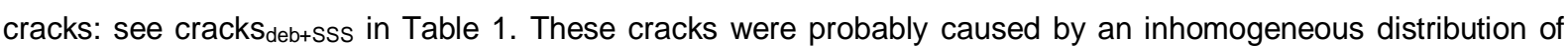
alumina and binder material in the composite starting powder or by the occurrence of other phenomena which induced swelling during the debinding process. Probably, this swelling was caused by a too high green density, 
which hindered the gases formed during the debinding step to escape, in combination with (i) a too high amount of binder material, (ii) the presence of solvents used during powder production and/or (iii) the presence of moisture in the starting powder. Optimizing the binder removal and SSS process parameters might reduce the amount and size of the cracks and result in slightly increased final densities.

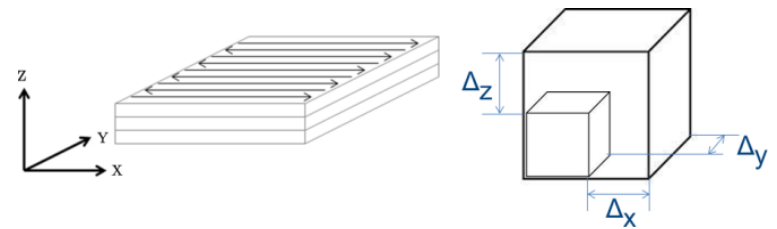

Figure 9: Shrinkage in the scan ' $x$ ', cross-scan 'y' and build 'z' directions (Deckers et al., 2013).

\subsection{Densification processes}

The main drawback of producing technical ceramic parts through indirect SLS of dry composite powder agglomerates, was the presence of inter-agglomerate pores in the final parts. These pores were already present as voids between the agglomerates at the beginning of the PM process (Figure 10). Since the inter-agglomerate pores could not be eliminated during the SLS, debinding and SSS steps, the following densification steps were investigated to produce ceramic parts with an increased density: remelting, isostatic pressing and infiltration (Figure 1). Figure 4 illustrates at which stages of the PM process, the different densification steps were performed: remelting was performed after SLS of individual layers; isostatic pressing was performed before debinding; infiltration could be performed after SLS of the full green part, after a debinding and pre-sintering step in a furnace $\left(1050^{\circ} \mathrm{C}\right)$ and after SSS in a furnace $\left(1600^{\circ} \mathrm{C}\right)$.

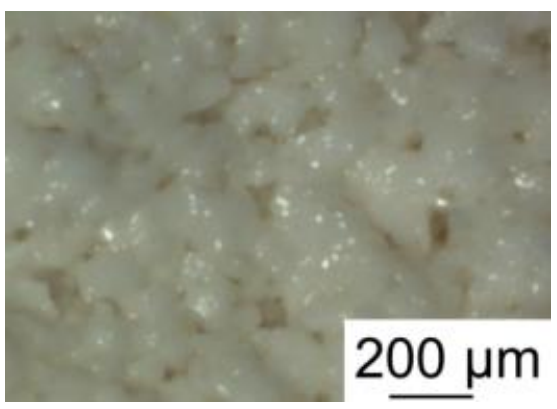

(a)

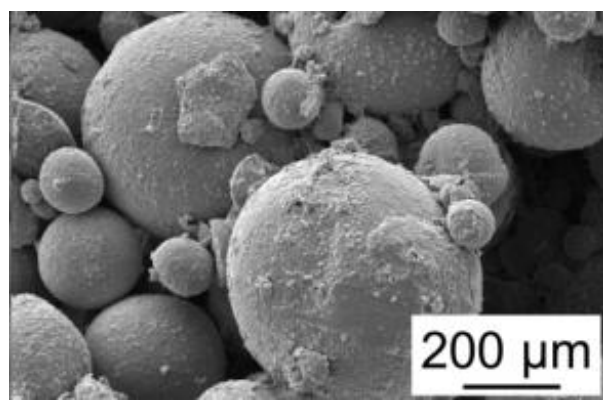

(b)

Figure 10: 3D microcope image of inter-agglomerate pores in an SLSed part, produced with the $\mathrm{Al}_{2} \mathrm{O}_{3}$ - carnauba wax - low density polyethylene powder (a) and inter-agglomerate pores in the alumina part after debinding and solid state sintering a part produced with the $\mathrm{Al}_{2} \mathrm{O}_{3}-\mathrm{PP}$ powder (b). 
Table 2: Porosities after SLS, densities after furnace solid state sintering (SSS) and linear shrinkages of the cubic $\left(10 \times 10 \times 10 \mathrm{~mm}^{3}\right)$ alumina parts after additional densification steps. The dimensional shrinkages of the table indicate the geometrical changes that appear after the SLS process, i.e. the geometry after SLS is the reference geometry (NM=not measured). The density/porosity of the parts, marked by *, were measured by the geometrical method. Other densities were measured by the Archimedes method. The occurrence of cracks after SSS is also denoted.

\begin{tabular}{|c|c|c|c|c|c|c|c|}
\hline $\begin{array}{l}\text { Part } \\
\mathrm{nr}\end{array}$ & Powder & $\begin{array}{l}\text { Additional densification steps } \\
\text { (besides SLS, deb. and FS) }\end{array}$ & $\begin{array}{l}\text { porositysLS } \mathrm{e}^{*} \\
{[\%]}\end{array}$ & $\begin{array}{l}\rho_{S s s}{ }^{*} \\
{[\%]}\end{array}$ & $\begin{array}{l}x-y \\
{[\%]}\end{array}$ & $\begin{array}{l}z \\
{[\%]}\end{array}$ & Cracks \\
\hline 1 & $\mathrm{Al}_{2} \mathrm{O}_{3}-\mathrm{PA}(\mathrm{BM})$ & None, i.e. only deb. and FS & $63 \% *$ & NM & NM & NM & NM \\
\hline 2 & $\mathrm{Al}_{2} \mathrm{O}_{3}-\mathrm{PS}$ & None, i.e. only deb. and FS & $34 \%$ & $66 \%$ & $-31 \%$ & $-44 \%$ & macro \\
\hline 3 & $\mathrm{Al}_{2} \mathrm{O}_{3}-\mathrm{PA}(\mathrm{TIPS})$ & None, i.e. only deb. and FS & $45 \% *$ & $47 \%$ & $-21 \%$ & $-24 \%$ & no \\
\hline 4 & $\mathrm{Al}_{2} \mathrm{O}_{3}-\mathrm{PP}$ & None, i.e. only deb. and FS & $49 \%$ & $39 \%$ & $-20 \%$ & $-21 \%$ & no \\
\hline 5 & $\mathrm{Al}_{2} \mathrm{O}_{3}$-carn.+PE & None, i.e. only deb. and FS & $34 \%$ & $77 \%$ & $-21 \%$ & $-26 \%$ & no \\
\hline $6-23$ & $\mathrm{Al}_{2} \mathrm{O}_{3}-\mathrm{PA}$ (TIPS) & Laser remelting & $39-44 \%$ & $47-51 \%$ & -18 to $-23 \%$ & -12 to $-25 \%$ & no \\
\hline $24-32$ & $\mathrm{Al}_{2} \mathrm{O}_{3}-\mathrm{PA}(\mathrm{BM})$ & $\mathrm{CIP}_{200 \mathrm{MPa}, 1 \mathrm{~min}}$ & $61-65 \% *$ & $83-90 \% *$ & -35 to $-47 \%$ & -45 to $-61 \%$ & macro \\
\hline $33-36$ & $\mathrm{Al}_{2} \mathrm{O}_{3}-\mathrm{PA}(\mathrm{TIPS})$ & $\mathrm{CIP}_{100-200} \mathrm{MPa}, 5 \mathrm{~min}$. & $45-46 \%$ * & $53-62 \% *$ & -20 to $-27 \%$ & -32 to $-33 \%$ & NM \\
\hline $37-38$ & $\mathrm{Al}_{2} \mathrm{O}_{3}-\mathrm{PA}(\mathrm{BM})$ & $\mathrm{QIP}_{165^{\circ} \mathrm{C}, 20 \mathrm{MPa}, 5-15 \mathrm{~min} .}$ & NM & $89-93 \% *$ & NM & NM & NM \\
\hline $39-42$ & $\mathrm{Al}_{2} \mathrm{O}_{3}-\mathrm{PA}$ (TIPS) & $\mathrm{QIP}_{100^{\circ} \mathrm{C}-160^{\circ} \mathrm{C}, 50 \mathrm{MPa}, 5-30 \mathrm{~min} .}$ & $41-46 \% *$ & $53-63 \% *$ & -13 to $-27 \%$ & -33 to $-46 \%$ & NM \\
\hline $43-44$ & $\mathrm{Al}_{2} \mathrm{O}_{3}-\mathrm{PS}$ & 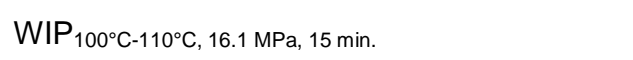 & $33-34 \%$ & $48-52 \%$ & $-22 \%$ to $-24 \%$ & -23 to $-24 \%$ & macro \\
\hline 45 & $\mathrm{Al}_{2} \mathrm{O}_{3}-\mathrm{PA}(\mathrm{TIPS})$ & $\mathrm{WIP}_{110^{\circ} \mathrm{C}, 16.1 \mathrm{MPa}, 30 \mathrm{~min} .}$ & $48 \%$ & $62 \%$ & $-29 \%$ & $-29 \%$ & macro \\
\hline 46 & $\mathrm{Al}_{2} \mathrm{O}_{3}-\mathrm{PP}$ & $\mathrm{WIP}_{140^{\circ} \mathrm{C}, 48 \mathrm{MPa}, 15 \mathrm{~min} .}$ & $54 \%$ & $64 \%$ & $-27 \%$ & $-35 \%$ & no \\
\hline 47 & $\mathrm{Al}_{2} \mathrm{O}_{3}-\mathrm{PP}$ & $\mathrm{WIP}_{135^{\circ} \mathrm{C}, 64 \mathrm{MPa}, 5 \mathrm{~min} .}$ & $62 \%$ & $88 \%$ & NM & NM & no \\
\hline 48 & $\mathrm{Al}_{2} \mathrm{O}_{3}$-carn.+PE & $\mathrm{WIP}_{60^{\circ} \mathrm{C}, 48 \mathrm{MPa}, 15 \mathrm{~min}}$ & $39 \%$ & $83 \%$ & $-25 \%$ & $-30 \%$ & yes \\
\hline 49 & $\mathrm{Al}_{2} \mathrm{O}_{3}-\mathrm{PA}(\mathrm{TIPS})$ & Inf.green, pressureless, 30 vol\%, 4 hours & $48 \%$ & $48 \%$ & $-15 \%$ & $-16 \%$ & no \\
\hline 50 & $\mathrm{Al}_{2} \mathrm{O}_{3}-\mathrm{PS}$ & Inf.green, pressureless, 30 vol\%, 4 hours & $32 \%$ & $54 \%$ & $-24 \%$ & $-23 \%$ & macro \\
\hline 51 & $\mathrm{Al}_{2} \mathrm{O}_{3}-\mathrm{PA}(\mathrm{TIPS})$ & Inf. after pre-sint., pressureless, 30 vol\%, 4 hours & $46 \%$ & $63 \%$ & $-25 \%$ & $-26 \%$ & no \\
\hline 52 & $\mathrm{Al}_{2} \mathrm{O}_{3}-\mathrm{PS}$ & Inf. after pre-sint., pressureless, 30 vol\%, 4 hours & $32 \%$ & $71 \%$ & $-32 \%$ & $-37 \%$ & macro \\
\hline 53 & $\mathrm{Al}_{2} \mathrm{O}_{3}-\mathrm{PS}$ & Inf.green, $48 \mathrm{MPa}, 40$ vol\%, $5 \mathrm{~min}$ & $34 \%$ & $53 \%$ & $-20 \%$ & $-16 \%$ & NM \\
\hline 54 & $\mathrm{Al}_{2} \mathrm{O}_{3}-\mathrm{PP}$ & Inf.green, $13 \mathrm{MPa}, 30$ vol\% & NM & $63 \%$ & NM & NM & no \\
\hline 55 & $\mathrm{Al}_{2} \mathrm{O}_{3}-\mathrm{PP}$ & Inf.green, $2 \mathrm{MPa}, 40$ vol\%, 5 min. & NM & $71 \%$ & NM & NM & macro \\
\hline 56 & $\mathrm{Al}_{2} \mathrm{O}_{3}-\mathrm{PS}$ & Inf. green \& after pre-sint., $48 \mathrm{MPa}, 40$ vol\%, $5 \mathrm{~min}$. & $34 \%$ & $80 \%$ & $-22 \%$ & $-18 \%$ & micro \\
\hline 57 & $\mathrm{Al}_{2} \mathrm{O}_{3}-\mathrm{PS}$ & Inf.green \& after SSS, $48 \mathrm{MPa}, 40$ vol\%, $5 \mathrm{~min}$. & $34 \%$ & $61 \%$ & $-21 \%$ & $-16 \%$ & NM \\
\hline 58 & $\mathrm{Al}_{2} \mathrm{O}_{3}-\mathrm{PP}$ & Inf.green, $13 \mathrm{MPa}, 30$ vol\% $+\mathrm{WIP}_{135^{\circ} \mathrm{C}, 64 \mathrm{MPa}, 5 \mathrm{~min} \text {. }}$ & NM & $86 \%$ & NM & NM & no \\
\hline 59 & $\mathrm{Al}_{2} \mathrm{O}_{3}-\mathrm{PP}$ & Inf.green, vac., 40 vol\%, $100 \mathrm{~s}$ & $53 \%$ & $63 \%$ & $-14 \%$ & $-13 \%$ & no \\
\hline 60 & $\mathrm{Al}_{2} \mathrm{O}_{3}-\mathrm{PP}$ & Inf. $2 x$ green, vac., 40 vol\%, $100 \mathrm{~s}$ & $54 \%$ & $74 \%$ & $-16 \%$ & $-16 \%$ & no \\
\hline 61 & $\mathrm{Al}_{2} \mathrm{O}_{3}$-carn.+PE & Inf.green, vac., 40 vol\%, $100 \mathrm{~s}$ & $33 \%$ & $80 \%$ & $-19 \%$ & $-14 \%$ & macro \\
\hline 62 & $\mathrm{Al}_{2} \mathrm{O}_{3}$-carn.+PE & Inf. $2 x$ green, vac., 40 vol\%, $100 \mathrm{~s}$ & $32 \%$ & $81 \%$ & $-19 \%$ & $-19 \%$ & micro \\
\hline 63 & $\mathrm{Al}_{2} \mathrm{O}_{3}-\mathrm{PP}$ & Inf. $3 x$ after pre-sint., vac., 40 vol\%, $100 \mathrm{~s}$ & $53 \%$ & $91 \%$ & $-15 \%$ & $-19 \%$ & no \\
\hline 64 & $\mathrm{Al}_{2} \mathrm{O}_{3}$-carn.+PE & Inf. $3 x$ after pre-sint., vac., 40 vol\%, $100 \mathrm{~s}$ & $37 \%$ & $78 \%$ & $-19 \%$ & $-26 \%$ & macro \\
\hline 65 & $\mathrm{Al}_{2} \mathrm{O}_{3}-\mathrm{PP}$ & Inf. green \& $3 x$ after pre-sint., vac., 40 vol\%, $100 \mathrm{~s}$ & $51 \%$ & $81 \%$ & $-19 \%$ & $-18 \%$ & no \\
\hline 66 & $\mathrm{Al}_{2} \mathrm{O}_{3}$-carn.+PE & Inf. green \& $3 x$ after pre-sint., vac., 40 vol\%, $100 \mathrm{~s}$ & $37 \%$ & $67 \%$ & $-14 \%$ & $-15 \%$ & no \\
\hline 67 & $\mathrm{Al}_{2} \mathrm{O}_{3}-\mathrm{PP}$ & 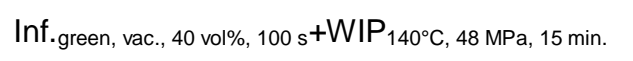 & $51 \%$ & $79 \%$ & $-17 \%$ & $-18 \%$ & no \\
\hline 68 & $\mathrm{Al}_{2} \mathrm{O}_{3}$-carn.+PE & 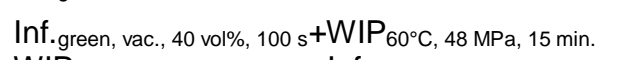 & $34 \%$ & $88 \%$ & $-21 \%$ & $-18 \%$ & micro \\
\hline 69 & $\mathrm{Al}_{2} \mathrm{O}_{3}-\mathrm{PP}$ & $\begin{array}{l}\text { WIP } 140^{\circ} \mathrm{C}, 48 \mathrm{MPa}, 15 \mathrm{~min} .+\operatorname{lnf} .3 \mathrm{x} \text { after pre-sint., vac., } 40 \\
\text { vol\%, } 100 \mathrm{~s}\end{array}$ & $54 \%$ & $70 \%$ & NM & NM & no \\
\hline 70 & $\mathrm{Al}_{2} \mathrm{O}_{3}$-carn.+PE & $\begin{array}{l}\text { WIP } 60^{\circ} \mathrm{C}, 48 \mathrm{MPa}, 15 \mathrm{~min} .+ \text { Inf. } 3 \mathrm{x} \text { after pre-sint., vac., } 40 \\
\text { vol\%, } 100 \mathrm{~s}\end{array}$ & $32 \%$ & $89 \%$ & $-20 \%$ & $-27 \%$ & micro \\
\hline
\end{tabular}




\subsubsection{Isostatic pressing}

Cold isostatic (CIP), quasi isostatic (QIP) and warm isostatic (WIP) pressing of the SLSed parts all resulted in an increase of the green density: e.g. WIP decreased the porosity of parts 46,47 and 48 respectively from $54 \%$, $62 \%$ and $39 \%$ down to $12 \%, 8 \%$ and $10 \%$. In this study, the pressure applied during the CIP experiments (up to $200 \mathrm{MPa}$ ) was high enough to plastically deform the powder agglomerates of the ball milled $\mathrm{Al}_{2} \mathrm{O}_{3}-\mathrm{PA}$ powder (Table 2: parts 24 to 32), but not high enough to plastically deform the $\mathrm{Al}_{2} \mathrm{O}_{3}-\mathrm{PA}$ powder produced through the TIPS process (Table 2: parts 33 to 36 ). By heating the SLSed parts during QIP experiments, the strength of the composite agglomerates decreased. As a result, similar densities as during the CIPing experiments were obtained at lower QIPing pressures (Table 2: compare parts 24 to 36, with parts 37 to 42). However, QIPing led to a uniaxial compression, resulting in a nonuniform shrinkage (Table 2: parts 39 to 42). WIP was a more promising IP technique than CIP and QIP, since an isostatic pressure could be uniformly applied on the SLSed samples (leading to a more uniform shrinkage: see e.g. parts 43 to 45 in Table 2) and the heated liquid allowed the binder material to be plastically deformed. For example, during WIPing at $135-140^{\circ} \mathrm{C}$, the alumina-PP composite agglomerates broke at a pressure between 48 and 64 MPa (Table 2: compare parts 46 and part 47). At a similar pressure, the alumina-carnauba wax-LDPE composite agglomerates broke at a WIPing temperature of $60^{\circ} \mathrm{C}$ (Table 2: part 48). It can be concluded that WIP was the most promising IP techique investigated in this study.

Many isostatically pressed parts cracked during debinding and SSS, although these parts did not crack without the IP step. Sometimes, the cracks could be attributed to improper vacuum packing. In this case, circular cracks arose after SSS, due to air entrapment during WIP (e.g. Table 2: part 45, Figure 11a). After IP, debinding and SSS, the parts obtained by SLS of the ball milled $\mathrm{Al}_{2} \mathrm{O}_{3}-\mathrm{PA}$ powder (CIP, Table 2: parts 24 to 32 ), the $\mathrm{Al}_{2} \mathrm{O}_{3}-\mathrm{PS}$ powder (WIP, Table 2: parts 43 and 44) and the $\mathrm{Al}_{2} \mathrm{O}_{3}$-carnauba_wax-LDPE powder (WIP, Table 2: part 48, Figure 11b) contained non-circular cracks. These cracks could be attributed to swelling during the debinding process or inhomogeneous shrinkage during debinding and SSS. In the former case (circular cracks), the gases, formed during the thermal debinding step, could not escape from the dense, WIPed parts. In the latter case (noncircular cracks), the cracks were caused by an inhomogeneous distribution of alumina-binder concentrations in the composite starting powder.
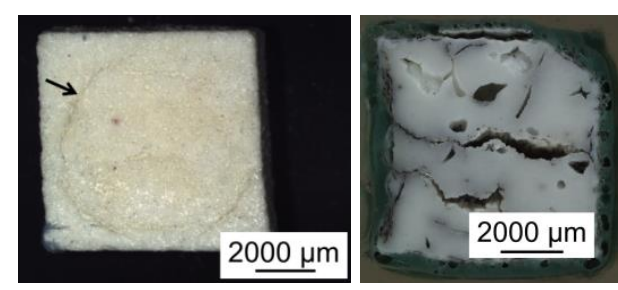

Figure 11: 3D microscope image of (a) the circular cracks in part 45 (Table 2) and (b) non-circular cracks in part 48 (Table 2), which were produced by WIPing parts produced through SLS of respectively $\mathrm{Al}_{2} \mathrm{O}_{3}-\mathrm{PA}$ (TIPS 1) and $\mathrm{Al}_{2} \mathrm{O}_{3}$-carnauba wax-LDPE powders. 
It can be concluded that breaking the composite agglomerates through WIP was not sufficient to produce high density and crack free alumina parts. As described in the next section, applying an infiltration step after SLS and before WIP could prevent the formation of large cracks during debinding and SSS.

\subsubsection{Infiltration}

The infiltration experiments revealed that both pressure infiltration (Table 2: parts 53 to 55 ) and vacuum infiltration (Table 2: parts 59 to 64 ) led to a better infiltration behavior (i.e. more suspension entering the pores of the part) compared to pressureless infiltration (Table 2: parts 49 to 52). It could not be determined whether pressure infiltration or vacuum infiltration was the best infiltration method. Perhaps, a combination of both methods is the most favorable: applying a vacuum prior to infiltration and applying an external pressure during infiltration.

Infiltrating multiple times led to higher final part densities (Table 2: compare parts 60 and 62 with respectively parts 59 and 61). Also, infiltration generally led to the formation of a dense outer shell and a more porous core (Figure 12). The formation of the dense shell could be explained assuming that (i) the infiltrated outer shell impeded further infiltration inwards, (ii) the viscosity of the suspension was too high and/or (iii) the infiltration time was too short to fully infiltrate the parts.

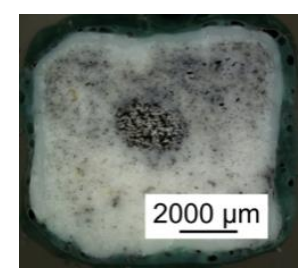

Figure 12: Part 63, produced by indirect SLS of the $\mathrm{Al}_{2} \mathrm{O}_{3}-\mathrm{PP}$ (TIPS 1) powder and 3 times vacuum infiltration of a 40 vol\% alumina suspension after pre-sintering.

As infiltration filled the pores of the parts, the shrinkage during subsequent debinding and/or solid state sintering was reduced, sometimes resulting in a reduction of the densities after solid state sintering. The experiments also revealed that infiltration after pre-sintering resulted in an increase of the part shrinkage as compared to infiltration immediately after SLS (Table 2). A possible explanation for this is that the part shrinkage during the debinding step was not prohibited if only infiltration after pre-sintering was applied. Further, the shell, formed due to infiltration, shrunk less than the more porous core during sintering. This non-uniform shrinkage sometimes led to the formation of internal cracks, usually cracks perpendicular to the build $\mathrm{z}$ direction and along the inter-layer porosities, and a lower sintered density.

As depicted in Table 2 and Figure 4, infiltration was performed at different stages of the PM process: after SLS, after the debinding and pre-sintering step at $1050^{\circ} \mathrm{C}$ and after SSS at $1600^{\circ} \mathrm{C}$. Since infiltration was a more effective densification step when applied on more porous parts, infiltration after pre-sintering, i.e. after the binder removal and the initial solid state sintering step, generally led to the highest density (higher than infiltrating after 
SLS or after furnace SSS): e.g. up to $91.4 \%$ for alumina parts produced with the $\mathrm{Al}_{2} \mathrm{O}_{3}-\mathrm{PP}$ powder (Figure 12 and Table 2: part 63). However, the strength of the parts during the debinding step was generally low. Green infiltration was sometimes needed to increase the strength of complex shapes during the debinding step (Figure 13). The strength of these shapes would be too low to bear its own weight.

When infiltration was only applied once during the PM process, the best stage to infiltrate depended on the complexity of the part: for non-complex shaped parts the best stage to infiltrate was after pre-sintering (i.e. highest density), and for complex shaped parts the best stage to infiltrate was after SLS (i.e. increased density and sufficient strength during debinding). The feasibility to infiltrate not once, but at different stages of the PM process, was also investigated as explained in section 3.3.3.

\subsubsection{Combination of different densification steps}

The combined influence of infiltration after SLS, warm isostatic pressing, infiltration after pre-sintering and/or infiltration after SSS was investigated (Table 2: parts 56 to 58 and parts 65 to 70 ). After green infiltration, already filled inter-agglomerate pores and the dense shell prohibited the infiltration after pre-sintering or SSS. Also, since WIPing decreased the pore size after pre-sintering, the infiltrant could not flow inside the part anymore. Therefore, it can be concluded that infiltration after pre-sintering or SSS was a non-effective densification step when applied after a green infiltration and/or WIPing step.

Since green infiltration increased the strength and prohibited the formation of cracks during the debinding step, applying green infiltration before WIP seemed to be the most successful combination of densification steps for complex shapes (see also Table 2: parts 58, 67 and 68). For example, after furnace sintering this combination led to densities up to $88 \%$ for alumina parts produced with the $\mathrm{Al}_{2} \mathrm{O}_{3}$-carnauba wax-LDPE powder (Table 2: part 68). Moreover, the flexural strength of parts produced by SLS of the $\mathrm{Al}_{2} \mathrm{O}_{3}-\mathrm{PP}$ powder/WIPing/debinding/sintering (i.e. same PM process as part 58 in Table 2) was 148 \pm 20 MPa (Shahzad et al., 2013).

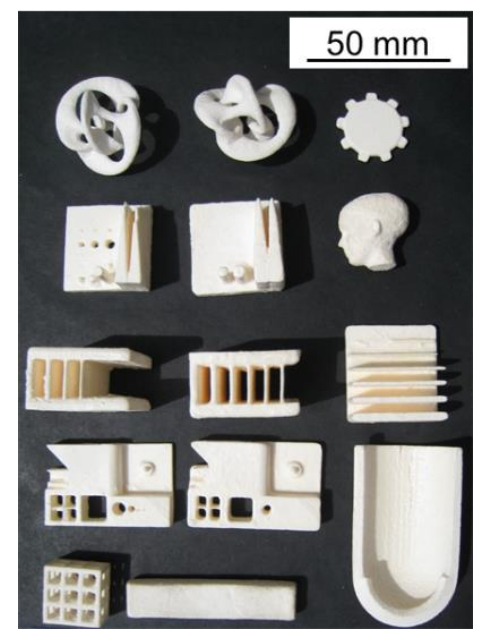

Figure 13: Overview of complex shape parts produced by SLS of $\mathrm{Al}_{2} \mathrm{O}_{3}-\mathrm{PP}$ (TIPS 1) powder, pressure infiltration with a 40 vol $\% \mathrm{Al}_{2} \mathrm{O}_{3}$ suspension, debinding and SSS. 


\section{DISCUSSION}

\subsection{Selective laser sintering}

From all the powder production routes investigated in this paper to produce composite powder agglomerates to indirect SLS alumina parts, the TIPS process seemed to be the most appropriate. Firstly, the agglomerates produced by the TIPS process had a near-spherical shape and could be well deposited by the counter current roller of the DTM Sinterstation 2000. Secondly, the TIPS process seemed to be very flexible, as composite agglomerates containing different binders (PA, PP, carnauba wax and LDPE) could be produced. The TIPS process could also be applied to other ceramics than alumina. For example, although not described in this paper, $\mathrm{ZrO}_{2}$ parts were fabricated from $\mathrm{ZrO}_{2}-\mathrm{PP}$ agglomerates produced by TIPS (Shahzad et al., 2014).

It seemed that SLS of composite powders, containing low viscosity binders, resulted in green parts with the highest green density (Table 1). During the SLS process, the low viscosity binders could fill the inter-agglomerate pores. Furthermore, the density after debinding and furnace sintering was generally also the highest for the parts with the highest green density after SLS. From all the binder materials investigated, the carnauba wax containing binders had the lowest viscosity during SLS and the highest density after SSS. Nevertheless, due to its low viscosity, a base plate and the addition of LDPE was needed during respectively SLS and debinding. In this way, the low viscosity of the carnauba wax made the production of complex shapes more difficult.

In this study, PS seemed to be the most appropriate binder material to fabricate high density, complex shaped alumina parts through SLS of dry composite powders without using a base plate, followed by a debinding and SSS step. The viscosity of PS was high enough to have a relatively high green density after SLS at low temperatures, and low enough to avoid the use of a base plate. However, as only composite agglomerates, containing a large amount of PS (71vol\%) were investigated and the alumina parts produced by the alumina-PS powder contained cracks (Table 2), further research is needed to prove this statement. In order to do so, aluminaPS composite powder, produced by the TIPS process rather than dispersion polymerization, should be investigated.

\subsection{Post SLS processing}

During the PM processes described above, material was removed (debinding) and added (infiltration) to the SLSed part. The mass of a ceramic part after solid state sintering, $\mathrm{m}_{\mathrm{sss}}$, was a function of the mass after SLS, $\mathrm{m}_{\mathrm{SLS}}$, the mass of the binder, $\mathrm{m}_{\text {binder, }}$ inside the SLSed part and the (dry) mass of the infiltrant material added during infiltration, $m_{\text {inf. }}$ This can be expressed by the following equation:

$$
m_{S S S}=m_{S L S}-m_{\text {binder }}+m_{\text {inf. }} \text { Equation } 2
$$

This formula can be rewritten to correlate the density change and the part shrinkage after SLS as: 


$$
\rho_{\mathrm{SSS}, \mathrm{a}}=\frac{\rho_{\mathrm{SLS}, \mathrm{a}}}{\rho_{\mathrm{SLS}, \max }} \cdot \frac{\rho_{\mathrm{SLS}, \max }-\rho_{\text {binder }} \cdot \mathrm{vol} \% \text { binder }+\rho_{\text {inf. }} \cdot \mathrm{vol} \% \text { inf. }}{1+\operatorname{vol} \% \text { shrinkage }} \text { Equation } 3
$$

with:

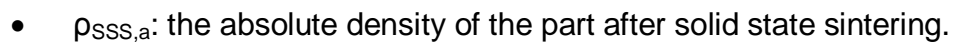

- $\rho_{S L S, a:}$ the absolute density of the part after selective laser sintering.

- $\rho$ SLS,max: the maximal possible (absolute) density of the part after selective laser sintering: i.e. the density of an SLSed part without pores.

- $\rho_{\text {binder: }}$ the (absolute) density of the binder material.

- vol\% binder: the volume binder material in the SLSed part, relative to the 'internal' volume (i.e. not including pores) of the SLSed material.

- $\rho_{\text {inf: }}$ the (absolute) density of the (dry) infiltrant material: e.g. $3.984 \mathrm{~g} / \mathrm{cm}^{3}$ for alumina.

- vol\% inf.: the volume (dry) infiltrant material which entered the part during subsequent infiltration steps (i.e. after SLS, pre-sintering and/or SSS), relative to the 'internal' volume of the SLSed material.

- $1+$ vol\% shrinkage: the 'external' volume (i.e. including pores) of the part after solid state sintering, relative to the 'external' volume of the SLSed part. The volumetric shrinkage (vol\% shrinkage), caused by solid state sintering, can be calculated from the $\%$ linear shrinkage in the $x, y$ and $z$ directions:

$1+$ vol\% shrinkage $=(1+\% \text { linear shrinkage })_{x} \cdot(1+\% \text { linear shrinkage })_{y} \cdot(1+\% \text { linear shrinkage })_{z}$ Equation 4

In general, the mass of a part at the end of the PM process can always be written as a function of the mass of the part after the primary shaping step and (possible) mass addition/removal during the subsequent PM processing steps. This means that similar equations as Equation 2 and Equation 3 can be formulated for all PM processes.

In order to verify Equation 3, the measured density $\rho_{\text {meas. }}$ after SSS of a selection of parts produced in this study, was compared with the corresponding calculated density $\rho_{\text {calc. }}$. As depicted in Table 3 , in about half of the cases, Equation 3 could predict quite accurately the final density of the parts. In the other half of the cases, Equation 3 seemed to be less accurate and differences of about 10\% could be observed between the measured and calculated relative density.

These differences could originate from (i) Dimensional measurement errors: the dimensions of the SLSed and SSS parts were (mostly) measured by a vernier caliper. Therefore the \% linear shrinkages calculated in this study could vary 1 or $2 \%$. As the vol\% shrinkage in Equation 4 was calculated by multiplying the \% linear shrinkage in scan $x$, cross-scan $y$ and build $z$ directions, these errors could accumulate. Furthermore, for the calculation of the vol\% shrinkage, it was assumed that the parts had flat side and top surfaces. Part distortion (e.g. introduced during isostatic pressing) could make this assumption not valid anymore. (ii) Density measurement errors: similar 
to the dimensional measurements performed in this study, the measured densities might vary 1 or $2 \%$. (iii) Assumptions made on the theoretical density of the binder and infiltrant materials. (iv) Degradation of polymer material during the SLS process: for the calculation of the densities after SLS, it was assumed that the binder did not degrade during SLS. (v) Erosion of the parts during manipulation. (vi) During many furnace treatments (debinding and SSS), the SLSed parts were positioned on coarse alumina powder. Especially when low viscosity binders were used, the binder possibly flowed into this coarse powder during the debinding step. The concomitant sticking of some coarse powder particles to the part, might lead to inaccurate density or dimensional measurements.

Table 3: Comparison of the measured density, $\rho_{\text {meas., }}$ after SSS of a selection of parts produced in this study, with the corresponding density, $\rho_{\text {calc. }}$, calculated according to Equation 3.

\begin{tabular}{|c|c|c|c|c|}
\hline $\begin{array}{l}\text { Part } \\
\mathrm{nr}\end{array}$ & powder & $\begin{array}{l}\text { Additional densification steps } \\
\text { (besides SLS, deb. and FS) }\end{array}$ & $\begin{array}{l}\rho_{\text {meas. }} \\
{[\%]}\end{array}$ & $\begin{array}{l}\rho_{\text {calc. }} \\
{[\%]}\end{array}$ \\
\hline 2 & $\mathrm{Al}_{2} \mathrm{O}_{3}-\mathrm{PS}$ & None, i.e. only deb. and FS & $66 \%$ & $72 \%$ \\
\hline 3 & $\mathrm{Al}_{2} \mathrm{O}_{3}-\mathrm{PA}$ (TIPS) & None, i.e. only deb. and FS & $47 \%$ & $46 \%$ \\
\hline 4 & $\mathrm{Al}_{2} \mathrm{O}_{3}-\mathrm{PP}$ & None, i.e. only deb. and FS & $39 \%$ & $40 \%$ \\
\hline 5 & $\mathrm{Al}_{2} \mathrm{O}_{3}$-carn.+PE & None, i.e. only deb. and FS & $77 \%$ & $66 \%$ \\
\hline 46 & $\mathrm{Al}_{2} \mathrm{O}_{3}-\mathrm{PP}$ & $\mathrm{WIP}_{140^{\circ} \mathrm{C}, 48 \mathrm{MPa}, 15 \mathrm{~min} .}$ & $64 \%$ & $53 \%$ \\
\hline 48 & $\mathrm{Al}_{2} \mathrm{O}_{3}$-carn.+PE & $\mathrm{WIP}_{60^{\circ} \mathrm{C}, 48 \mathrm{MPa}, 15 \mathrm{~min} .}$ & $83 \%$ & $71 \%$ \\
\hline 59 & $\mathrm{Al}_{2} \mathrm{O}_{3}-\mathrm{PP}$ & Inf. green, vac., 40 vol\%, $100 \mathrm{~s}$ & $63 \%$ & $64 \%$ \\
\hline 60 & $\mathrm{Al}_{2} \mathrm{O}_{3}-\mathrm{PP}$ & Inf. 2x green, vac., 40 vol\%, $100 \mathrm{~s}$ & $74 \%$ & $73 \%$ \\
\hline 61 & $\mathrm{Al}_{2} \mathrm{O}_{3}$-carn.+PE & Inf. green, vac., 40 vol\%, $100 \mathrm{~s}$ & $80 \%$ & $82 \%$ \\
\hline 62 & $\mathrm{Al}_{2} \mathrm{O}_{3}$-carn.+PE & Inf. $2 x$ green, vac., 40 vol\%, $100 \mathrm{~s}$ & $81 \%$ & $95 \%$ \\
\hline
\end{tabular}

Although Equation 3 could not be validated by all results, it provided insight in how the density of the SSS parts was influenced by the composite powder, the SLS process and the different densification steps. For example:

The more binder present in the composite powder (vol\% binder $\uparrow$ ), the more material degraded during the debinding step (- $\rho_{\text {binder }}$. vol\% binder $\downarrow$ ). As a result, the density after SSS decreased ( $\left.\rho_{s s s, a} \downarrow\right)$ if the concomitant increase of part shrinkage could not compensate for this phenomenon. However, a higher amount of binder material in the composite powder tended to increase the green density during SLS $\left(\rho_{S L S, a} \uparrow\right)$. As a result, also the density after SSS tended to increase ( $\left.\rho_{\mathrm{sss}, \mathrm{a}} \uparrow\right)$.

SLS with a sufficiently high laser energy density led to plastic flow of the binder material and increase of the green density after SLS ( $\left.\rho_{\text {SLS,a }} \uparrow\right)$. As a result, also the density after SSS tended to increase ( $\rho_{S S S, a} \uparrow$ ). On the other hand, too high laser energy densities (e $\uparrow \uparrow$ ) could lead to binder degradation (vol\% binder $\downarrow$ and - $\rho_{\text {binder }}$. vol\% binder $\uparrow$ ) and concomitant formation of pores ( $\left.\rho_{\mathrm{SLS}, \mathrm{a}} \downarrow\right)$, which tended to respectively increase and decrease the density after SSS ( $\left.\rho_{\mathrm{SSS}, \mathrm{a}} \uparrow \downarrow\right)$. Binder degradation during SLS also increased the maximal possible absolute density of the SLSed part $\left(\rho_{\mathrm{SLS}, \max \uparrow} \uparrow\right.$ ). As a result, the laser energy density which resulted in the highest green 
density, did not always resulted in the highest density after SSS.

When comparing the different composite powders (section 3.1, Table 1), it could be generally stated that high densities after SLS led to high densities after SSS. However, due to the formation of inter-agglomerate pores, the green densities of the SLSed parts which could be successfully debinded, did not exceed $66 \%$. In order to further increase the green density of the SLSed parts, the inter-agglomerate pores should be eliminated. As depicted in section 3.3, densification techniques were explored to eliminate the inter-agglomerate pores. Alternatively, high densities can be obtained by either eliminating the inter-agglomerate pores during laser irradiation, either by preventing the formation of the inter-agglomerate pores during powder deposition. To eliminate the interagglomerate pores during laser irradiation, further research is needed on indirect SLS of composite agglomerates, containing low viscosity binders. To eliminate the formation of inter-agglomerate pores during powder depositing, the agglomerates should be broken during the deposition (e.g. by a powder compaction device) or fine (e.g. submicrometer sized) composite powder particles, instead of the large $(10-100 \mu \mathrm{m})$ composite agglomerates, should be deposited. In this way, also the amount of binder material needed to SLS parts of sufficient strength might be less. To deposit fine powder particles, clustering of the particles due to interparticle forces should be avoided by 'dry depositing' the particles (e.g. by a ring blade (Ebert et al., 2004)) or by 'wet depositing' powder containing slurries (e.g. by a tape casting or spray deposition device).

The elimination of inter-agglomerate pores after additive manufacturing is critical for all powder based AM processes. This means that similar techniques as described in this paragraph can be applied to improve the density obtained after other AM processes: e.g. SLS of pure polymers and SLS/SLM of metals.

According to Equation 3, the remelting experiments performed in this study led to similar results as the SLS tests. Although the green density of the parts could be significantly increased, the density after SSS was not.

Equation 3 also illustrates that CIP, QIP and WIP allowed to increase the density after SSS by increasing the vol\% shrinkage through applying an external pressure after the SLS step. As illustrated in section 3.3, it should be kept in mind that the vol\% shrinkage should be increased by applying a uniform external pressure (i.e. no QIP), preferably at an elevated temperature (WIP instead of CIP).

The amount of infiltrated material according to Equation 3 was linearly related to the density increase after SSS. However, due to a decrease of the porosity of the part, infiltration also decreased the part shrinkage. Especially when infiltration led to inhomogeneous shrinkage, e.g. due to the formation of a dense shell, the density of the sintered parts could decrease. The infiltration experiments revealed that infiltration was more effective, when applied on more porous parts. This means that in order to increase the final sintered density by infiltration, the density prior to infiltration should be as low as possible. However, for the fabrication of complex shaped parts, the green density and concomitant part strength should be high enough to enable part manipulation. According to Equation 3, a compromise should be found between the green density after SLS and 
the amount of material added during infiltration in order to optimize the density after SSS.

It can be concluded that the results of the experiments described in section 3 can be explained through Equation 3. As the density prior to infiltration should be as low as possible, non-complex shapes should be infiltrated at the stage of the PM process, where the density is the lowest (i.e. after the pre-sintering step). On the contrary, complex shapes that would break during debinding and/or part manipulation after pre-sintering, should be infiltrated after SLS (to fill the inter-agglomerate pores and increase the part strength) and be WIPed afterwards (to increase the vol\% shrinkage after SLS).

\section{CONCLUSION}

This paper investigated a large number of variants of the following PM processing routes for the production of ceramic parts by indirect SLS: (i) in-house powder production, (ii) SLS, (iii) binder removal, (iv) furnace sintering and alternative densification steps. The different stages of the PM processes were investigated through microscopical analysis (3D microscopy and SEM), and by assessing and analytically describing (Equation 3) the density change and the part shrinkage after SLS.

From all the powder production routes investigated (i.e. ball milling, dispersion polymerization and temperature induced phase separation), the temperature induced phase separation (TIPS) process seemed to be the most appropriate. Through TIPS, near-spherical shaped composite agglomerate of various polymer-ceramic compositions can be produced. From all the different binders investigated (PA, PS, PP and carnauba wax - low density polyethylene), PS seemed to be the most appropriate to fabricate high density, complex shaped alumina parts through SLS of dry composite powders without using a base plate, followed by a debinding and SSS step. The viscosity of PS was high enough to have a relatively high green density after SLS at low temperatures, and low enough to avoid the use of a base plate.

All green parts produced with those various powders, resulted after SLS in parts with inter-agglomerate pores. These pores could not be closed after subsequent binder removal and furnace sintering. In order to reduce the inter-agglomerate voids, the possibility to include the following densification steps into the PM process chain was explored: remelting, isostatic pressing (i.e. QIP, CIP and WIP) and pressureless, pressure and vacuum infiltration after SLS, pre-sintering at $1050^{\circ} \mathrm{C}$ and furnace sintering at $1600^{\circ} \mathrm{C}$. Remelting was found to significantly increase the density of parts after SLS, but not the density after debinding and solid state sintering. Although all investigated isostatic pressing techniques could increase the green density and the density after solid state sintering, WIPing was most preferred as it could uniformly increase the vol\% shrinkage after SLS by applying an external pressure at an elevated temperature (i.e. weakening the binder material). Both vacuum infiltration as pressure infiltration led to more suspension entering the pores of the part compared to pressureless infiltration. Filling the inter-agglomerate pores during infiltration led to a reduction of the shrinkage after SLS. Also, infiltration generally led to the formation of a dense outer shell and a more porous core. This could result in non-uniform 
shrinkage after SLS, lower sintered densities and crack formation. Infiltration was most effective when applied on more porous parts. By infiltrating non-complex shapes after the pre-sintering step, the highest densities after solid state sintering could be obtained (91\% density for part 63 in Table 2). Since green infiltration increased the strength and prohibited the formation of cracks during the debinding step, applying green infiltration before WIP seemed to be the most successful combination of densification steps for complex shapes. In this way parts, with a sintered density of approximately $90 \%$ (e.g. $88 \%$ for part 68 in Table 2) could be obtained. In order to produce higher quality ceramics through indirect SLS, the inter-agglomerate pores should be avoided or completely eliminated.

\section{REFERENCES}

http://www.baikowski.com/products.php. http://www.ceramics.nist.gov/srd/summary/scdaos.htm.

AGARWALA, M., KLOSTERMAN, D., OSBORNE, N. \& LIGHTMAN, A. 1999. Hard metal tooling via SFF of ceramics and powder metallurgy. SFF Symposium.

BAI, P., CHENG, J. \& LIU, B. 2005. Selective Laser Sintering of polymer-coated $\mathrm{Al}_{2} \mathrm{O}_{3} / \mathrm{ZrO}_{2} / \mathrm{TiC}$ ceramic powder. Trans. Nonferrous Met. Soc. China, 15, 261-265.

CARDON, L., DECKERS, J., VERBERCKMOES, A., RAGAERT, K., DELVA, L., SHAHZAD, K., VLEUGELS, J. \& KRUTH, J.-P. 2013. Polystyrene-coated alumina powder via dispersion polymerization for indirect selective laser sintering applications. Journal of Applied Polymer Science, 128, 2121-2128.

CHAKRAVARTHY, K. M. \& BOURELL, D. L. Binder development for indirect SLS of non metallics. Proceedings of the SFF Symposium, 2010.

DAS, S., BEAMAN, J. J., WOHLERT, M. \& BOURELL, D. L. 1998a. Direct laser freeform fabrication of high performance metal components. Rapid Prototyping Journal, 4, 112-117.

DAS, S., BEAMAN, J. J., WOHLERT, M. \& BOURELL, D. L. 1998b. Producing metal parts by Selective Laser Sintering/Hot Isostatic Pressing. JOM, 50, 17-20.

DAS, S., WOHLERT, M., BEAMAN, J. J. \& BOURELL, D. L. 1998c. Processing of Titanium Net Sapes by SLS/HIP.

DAS, S., WOHLERT, M., BEAMAN, J. J. \& BOURELL, D. L. 1999. Processing of titanium net shapes by SLS/HIP. Materials and design, 20, 115-121.

DECKERS, J., KRUTH, J.-P., CARDON, L., SHAHZAD, K. \& VLEUGELS, J. 2013. Densification and geometrical assessments of alumina parts produced through indirect Selective Laser Sintering of alumina-polystyrene composite powder. Strojniški vestnik - Journal of Mechanical Engineering, 59, 646-661.

DECKERS, J., KRUTH, J.-P., SHAHZAD, K. \& VLEUGELS, J. 2012a. Density improvement of alumina parts produced through selective laser sintering of alumina-polyamide composite powder. Annals of the CIRP, Manufacturing Technology, 61, 211-214.

DECKERS, J., SHAHZAD, K., VLEUGELS, J. \& KRUTH, J.-P. 2012b. Isostatic pressing assisted indirect selective laser sintering of alumina components. Rapid Prototyping Journal, 18, 409-419.

DRUMMER, D., RIETZEL, D. \& KÜHNLEINET, F. 2010. Development of a charcterization approach for the sintering behavior of new thermoplastics for selective laser sintering. Physics Procedia, 5, 533-542.

DU, Y. Y., SHI, Y. S. \& WEI, Q. S. 2010. Forming simulation and experimental verification of combined formation of Selective Laser Sintering and Cold Isostatic Pressing. Journal of Materials Science Engineering and Performance.

EBERT, R., EXNER, H., HARTWIG, L., KEIPER, B., KLÖTZER, S. \& REGENFUSS, P. 2004. International patent WO2004/076101 A2: Method and device for producing miniature bodies or microstructured bodies.

EVANS. 2005. Indirect rapid manufacturing of silicon carbide composites. The University of Texas Austin.

GALUSEK, D., SEDLACEK, J. \& RIEDEL, R. 2007. Al\$_2\$O\$3\$-SiC composites prepared by warm pressing and sintering of an organosilicon polymer coated alumina powder. Journal of European Ceramic Society, 27, 2385-2392.

GOODRIDGE, R. D., WOOD, D. J., OHTSUKI, C. \& DALGARNO, K. W. 2007. Biological evaluation of an apatite-mullite glass-ceramic produced via Selective Laser Sintering. Acta Biomaterialia, 3, 221-231. 
ISO/ASTM 17296 standard on Additive Manufacturing (AM) Technologies.

KRUTH, J.-P., DECKERS, J. \& YASA, E. 2008a. Experimental investigation of laser surface remelting for the improvement of Selective Laser Melting process.

KRUTH, J.-P., LEVY, G., KLOCKE, F. \& CHILDS, T. H. C. 2007. Consolidation phenomena in laser and powder-bed based layered manufacturing. Annals of the CIRP, 56, 730-759.

KRUTH, J.-P., YASA, E. \& DECKERS, J. 2008b. Roughness Improvement in Selective Laser Mel-ting.

KRUTH, J.-P., YASA, E. \& DECKERS, J. 2009. Experimental investigation of laser surface re-melting for the improvement of selective laser melting process.

LEE, I. 1998. Rapid full densification of alumina-glass composites fabricated by a Selective Laser Sintering process. Journal of Materials Science Letters, 17, 1907-1911.

LEE, I. 2002. Influence of heat treatment upon SLS processed composites fabricated with alumina and monoclinic $\mathrm{HBO}_{2}$. Journal of Materials Science Letters, 21, 209-212.

LEU, M. C., PATTNAIK, S. \& HILMAS, G. E. 2012. Investigation of Laser Sintering for freeform fabrication of zirconium diboride parts. Journal of Virtual and Physical Prototyping, 7, 25-36.

LIU, J., ZHANG, B., YAN, C. \& SHI, Y. 2010. The effect of processing parameters on characteristics of Selective Laser Sintering dental glass-ceramic powder. Rapid Prototyping Journal, 16, 138-145.

LIU, J. H., SHI, Y. S., LU, Z. L. \& HUANG, S. H. 2007a. Manufacturing near dense metal parts via indirect selective laser sintering combined with isostatic pressing. Appl. Phys. A, 89, 743-748.

LIU, Z. H., NOLTE, J. J., PACKARD, J. I., HILMAS, G., DOGAN, F. \& LEU, M. C. Selective Laser Sintering of high density alumina ceramic parts. Proceedings of the 35th MATADOR conference, 2007b. 351354.

LU, Z. L., SHI, Y. S., LIU, J. H., CHEN, Y. \& HUANG, S. H. 2008. Manufacturing AISI304 metal parts by indirect selective laser sintering combined with isostatic pressing. Int. J. Adv. Manuf. Technol., 39, $1157-1163$.

MUNRO, R. G. 1997. Evaluated material properties for a sintered alpha-Al\$_2\$O\$3\$.Journal of the American Ceramic Society, 80, 1919-1928.

OLEVSKY, E. A., MA, J., LASALVIA, J. C. \& MEYERS, M. A. 2007. Densification of porous bodies in a granular pressure-transmitting medium. Acta Materialia, 55, 1351-1366.

ROMBOUTS, M., DECKERS, J., THIJS, I., DECKX, J. \& KRUTH, J.-P. Wax based binder for indirect selective laser sintering of alumina. 5th International PMI Conference, 2012. 184-188.

SHAHZAD, K., DECKERS, J., BOURY, S., NEIRINCK, B., KRUTH, J.-P. \& VLEUGELS, J. 2012. Preparation and indirect selective laser sintering of alumina/PA microspheres. Ceramics International, 38, 1241-1247.

SHAHZAD, K., DECKERS, J., KRUTH, J.-P. \& VLEUGELS, J. 2013. Additive manufacturing of alumina parts by indirect selective laser sintering and post processing. Journal of Materials Processing Technology, 213, 1484-1494.

SHAHZAD, K., DECKERS, J., ZHANG, Z., KRUTH, J.-P. \& VLEUGELS, J. 2014. Additive manufacturing of zirconia parts by indirect selective laser sintering. Journal of the European Ceramic Society, 34, 81-89.

STEVINSON, B., BOURELL, D. L. \& BEAMAN, J. J. 2006a. Dimensional stability during post-processing of Selective Laser Sintered ceramic preforms. Virtual and Physical Prototyping, 1, 209-216.

STEVINSON, B. Y., BOURELL, D. L. \& BEAMAN, J. J. 2006b. Support-free infiltration of Selective Laser Sintered (SLS) silicon carbide preforms.

SUBRAMANIAN, K., VAIL, N., BARLOW, J. \& MARCUS, H. 1995. Selective Laser Sintering of alumina with polymer binders. Rapid Prototyping Journal, 1, 24-35.

TU, W. C. \& LANGE, F. E. 1995. Liquid precursor infiltration processing of powder compacts: kinetic studies and microstructure development. Journal of the American Ceramic Society, 78, 3277-3288.

WOHLERT, M., DAS, S., BEAMAN, J. J. \& BOURELL, D. L. 1999. Direct laser fabrication of high performance metal components via SLS/HIP.

YANG, H. C., LEE, J. W. \& KIM, K. R. 2004. Ruber isostatic pressing of metal powder under warm temperatures. Powder Technology, 134, 249-251.

YASA, E., DECKERS, J. \& KRUTH, J.-P. 2011a. The investigation of the influence of laser re-melting on density, surface quality and microstructure of selective laser melting parts. Rapid Prototyping Journal, 17, 312-327.

YASA, E., KRUTH, J.-P. \& DECKERS, J. 2011b. Manufacturing by combining Selective Laser Melting and Selective Laser Erosion / laser re-melting. CIRP Annals. Manufacturing Technology, 60, 263-266.

YOO, J., CIMA, M. J., KHANUJA, S. \& SACHS, E. M. 1993. Structural ceramic components by 3D Printing. SFF Symposium. 